\title{
Modelling and Vibration Analysis of Some Complex Mechanical Systems
}

\author{
Tadeusz Markowski ${ }^{1}$, Stanisław Noga ${ }^{1}$ and Stanisław Rudy ${ }^{2}$ \\ ${ }^{1}$ Rzeszów University of Technology \\ ${ }^{2}$ WSK PZL Rzeszów S.A.
}

Poland

\section{Introduction}

Development of modern engineering requires technical equipment which is characterized by high stability and operational dependability. This particularly applies to components and assemblies which are employed in the aviation, pharmaceutical and biotechnological industries, and biomedical devices. Each newly produced assembly must pass a cycle of advanced computations and a set of experimental tests which allow it to be used in engineering structures. In many cases the experimental tests are realized in order to verify the analytical results. For economic reasons, the calculations should be executed by using advanced computation techniques and the experimental investigations should be conducted on specially designed test rigs. Such test rigs are required to satisfy specific requirements to guarantee that experiments can be led with high technical quality, and economic reasons demand that the rigs should operate for a long period of time (Friswell \& Mottershead, 1995). One of the essential factors, which could disturb or restrict the functioning of devices (rigs and others), are the vibration of the components or assemblies of these systems. So it is advantageous to conduct numerical computations at the design stage, which could restrict the consequences connected with the structure vibration. The rapid development of computer techniques and analytical systems based on the finite element method (FEM) allows a free vibration analysis of large systems of complex design and geometry to be conducted (De Silva, 2005). Some authors, using FEM techniques, analyzed the free vibration of complex structures, which are used as load - bearing elements of building structures (Ansell, 2005). Free vibration analysis of selected steel bridges is conducted in papers of Chung and Živanovič (Chung \& Sotelino, 2006; Živanovič et al., 2007). The bridge FE models that are developed are verified on real objects. Zembaty (Zembaty et al., 2006) studied the influence of damage of the base construction frame on the change in the natural frequencies of the system. The gas turbine blade is a very important part of aviation jet engine. Some authors analyzed the influence of friction contact phenomenon in collaboration regions of blades and disk sectors on the dynamic behaviour of the blades (Allara, 2009; Toufine et al., 1999). Some presented results were verified by experimental tests. Free vibration of the blade are developed by Sinha (Sinha \& Turner, 2011) using the thin shell theory. The achieved solution includes the effect of warping of the cross - section of the blade. Membrane systems have wide application in different disciplines of engineering. Jaffrin and Tack in their papers (Jaffrin, 2008; Tack et al., 2006) present practical 
examples of the use of the membrane complex systems in the pharmaceutical, chemical and biotechnological industries, and biomedical devices. The fundamental theory of vibration of membrane systems is elaborated in a number of monographs for example by, Kaliski (Kaliski, 1966), Rao (Rao, 2007), and others. The classical theory of membranes is used by Rossit (Rossit et al., 1998) to solve the problem of the free vibration of composite membranes with discontinuously varying density. Noga (Noga, 2008) presents introductory studies that deal with the updating of the FE model of an annular membrane based on the analytical solution data. The complete analytical solutions of undamped free vibration of an elastically connected annular and circular double membrane compound systems are derived by Noga (Noga, 2010a).

The aim of this study is the analysis of the free vibration of selected mechanical systems with complex design and geometry. The present work is organized as follows. Section two gives basic overview of finite element technique for free vibration analysis. Section three presents the vibration problem of the fatigue test rig for aviation gear boxes. In section four the free vibration of the gas turbine blade are analyzed. Section five deals with the vibration problem of an annular membrane resting on an elastic foundation of a Winkler type. Section six gives some concluding remarks.

\section{Finite element technique in vibration problem}

The finite element (FE) technique is a useful tool to solve various dynamics problems. As mentioned earlier, the use of FE method allows the specific design feature and complex geometry of the system under study to be taken into consideration. The first step in any finite element analysis is to discretize the continuous models by building a discrete model of the physical structure to be analysed. It leads to the equations of motion of the analysed system that may be written in the following form (De Silva, 2005):

$$
\mathbf{M} \ddot{\mathbf{u}}+\mathbf{K u}=\mathbf{0}
$$

where $\mathbf{M}$ and $\mathbf{K}$ are, the global mass and global stiffness matrices (made up by proper assembly of the element matrices); $\ddot{\mathbf{u}}$ and $\mathbf{u}$ are the nodal acceleration and nodal displacement vector, respectively. Global mass and stiffness matrices are assembled from the element matrices that are given by (De Silva, 2005):

$$
\mathbf{M}^{(e)}=\int_{V^{(e)}} \rho^{(e)} \mathbf{N}^{T} \mathbf{N} d V^{(e)}, \quad \mathbf{K}^{(e)}=\int_{V^{(e)}} \mathbf{B}^{T} \mathbf{E B} d V^{(e)}
$$

where $\rho^{(e)}$ is the mass density coefficient for an element $e ; V^{(e)}$ is the volume of an element $e ; \mathbf{N}$ is the matrix of the element shape functions; $\mathbf{B}$ and $\mathbf{E}$ are, the element shape function derivatives, and the elasticity matrices, respectively. The natural frequencies of the system may be obtained by solving the eigenvalue problem

$$
\left(\mathbf{K}-\omega^{2} \mathbf{M}\right) \overline{\mathbf{u}}=\mathbf{0}
$$

where $\omega$ is the natural frequency and $\overline{\mathbf{u}}$ is the corresponding mode shape vector which can be obtained from equation (3). The number of eigenpairs $\left(\omega_{i}, \overline{\mathbf{u}}_{i}\right)$ corresponds to the number of degree of freedom of the system. The block Lanczos method is employed to solve the 
eigenvalue problem (3). Because of the discretization process, the FE models are treated as approximations of the exact systems. The error between the accurate and the FE models is defined by (Friswell \& Mottershead, 1995):

$$
\varepsilon=\left(\omega^{f}-\omega^{e}\right) / \omega^{e} \times 100[\%]
$$

where $\omega^{f}$ is the natural frequency from the FE analysis, while $\omega^{e}$ is the natural frequency of the exact system. Equation (4) is the so - called frequency error (Friswell \& Mottershead, 1995). For many systems with simple geometry, the exact value of the natural frequencies may be achieved from an analytical solution of the free vibration problem (Noga, 2010a, $2010 \mathrm{~b}$ ). Another possibility to determine the exact values of the natural frequencies is the execution of experimental investigation.

\section{Vibration of the fatigue test rig for aviation gearboxes}

The subject of this section is to analyse the free vibrations of a gear fatigue test rig working in a power circulating rig configuration. Markowski (Markowski et al., 2010) presents introductory studies that deal with the vibration of the system being studied. For this rig two FE models in the ANSYS system are made.

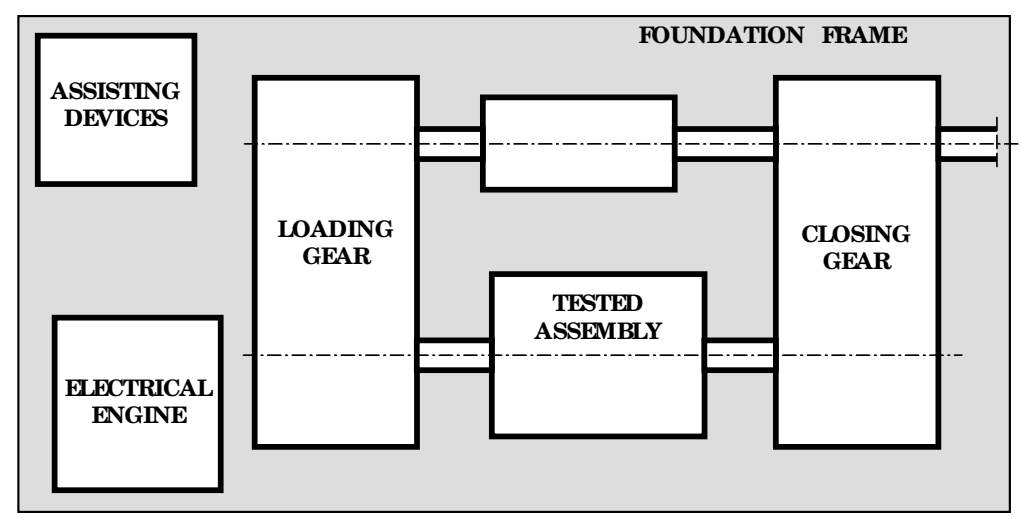

Fig. 1. The block diagram of the test rig

Based on the developed models, natural frequencies and mode shapes are determined. The received results are verified by the experiment. Some concluding remarks are provided.

\subsection{Description of the gear test rig working in closed loop configuration}

The test rig in question is created at the Test Bed Shop of the Wytwórnia Sprzętu Komunikacyjnego PZL Rzeszów S.A. A block diagram is presented in Fig. 1. All assemblies of the rig are mounted on metallic tables seated on the base frame, the design of which is demonstrated in Fig. 2. The frame consists of two layers of structural sections with a channel section welded together and fastened to the concrete base by anchors. The estimated weight of the base frame is $1600[\mathrm{~kg}]$. The full description of the base frame can be found in Markowski's paper (Markowski et al., 2010). 


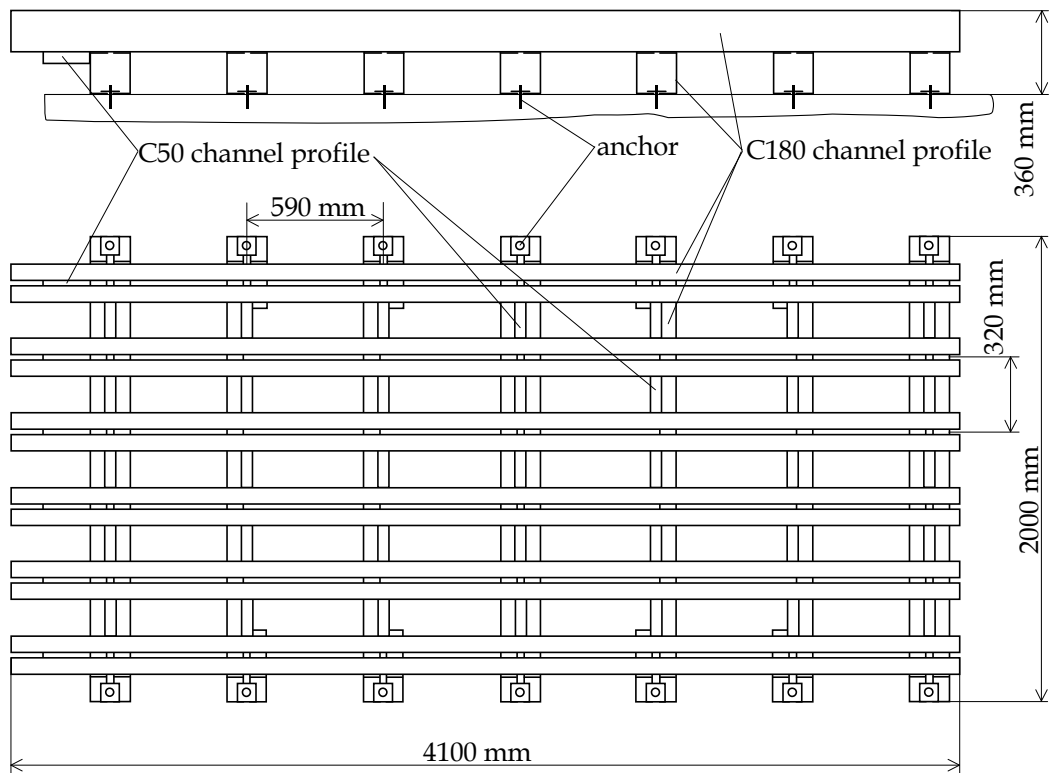

Fig. 2. Model of the base frame

Each additional steel table consisting of a structural $100 \times 100 \times 6$ square section or a

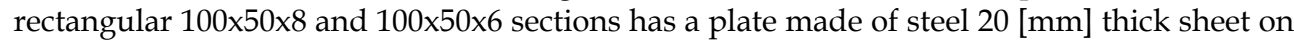
the upper end. All steel tables of the rig are welded. On the individual plates of the tables, the applicable assemblies of the rig are mounted together with additional features, used for the stability and accuracy of the rig assembly process. In Fig. 3, the rig under investigation is presented. The total estimated weight of the whole rig is $6500[\mathrm{~kg}]$. The rotating components of the rig are working in a rotating range of $2700-7500$ [rpm], which, if converted into number of cycles, equals $45-125[\mathrm{~Hz}]$ without considering the multiplication factor of the number of teeth. It was found that the assemblied rig vibrates under the influence of ground excitation, which is caused by the work of the neighboring test rigs. There was a real danger that those vibrations would disturb the rig operation.
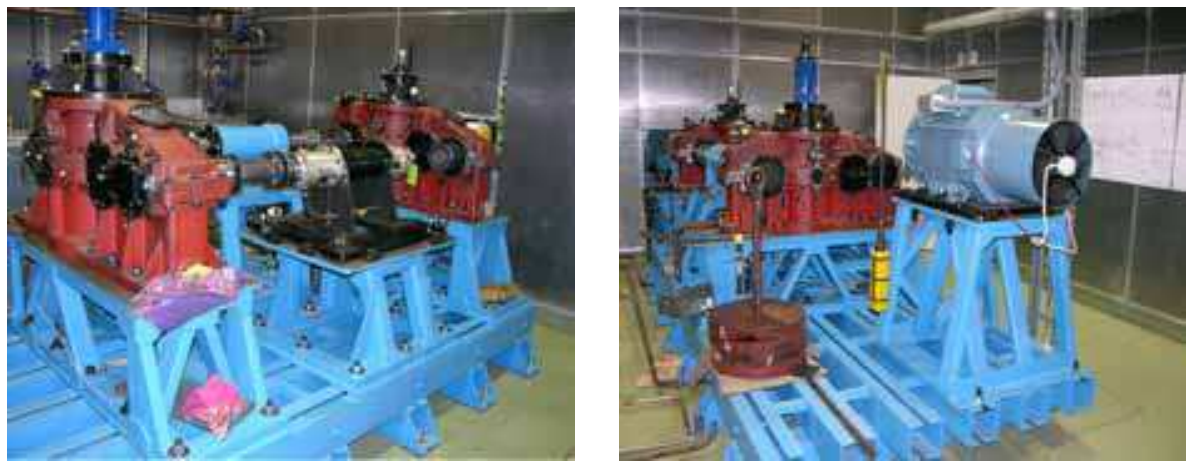

Fig. 3. Gear fatigue test rig overall view 
The necessity of the dynamic rig analysis was recognised in order to estimate its natural frequencies and mode shapes.

\subsection{Finite element representations of the system}

To obtain satisfactory modal analysis results, an accurate FE model of the system must be developed before conducting an experimental investigation on a real object. Such a primary dynamic overview of the system is helpful in planning and conducting the experimental investigation (De Silva, 2005; Friswell \& Mottershead, 1995). The investigated test rig is a complex system composed of various structural components. Therefore the primary aim is to develop an analytical model of the rig that has dynamic parameters (natural frequency and mode shapes) as close as possible to the parameters of a real object. From the economic point of view, the elaborated model should be so simple that the costs connected with its development and operations are kept at a bare minimum (Friswell \& Mottershead, 1995). Due to this fact, it is of high importance how crucial structural elements and rig assemblies are modelled, as well as, how proper FE elements are selected. From the test rig stability point of view, the base frame is an essential structural component (Fig. 2). This requires developing of a relatively precise FE model of the base frame. Two finite element models of the investigated system are prepared and discussed with the use of ANSYS FE code.
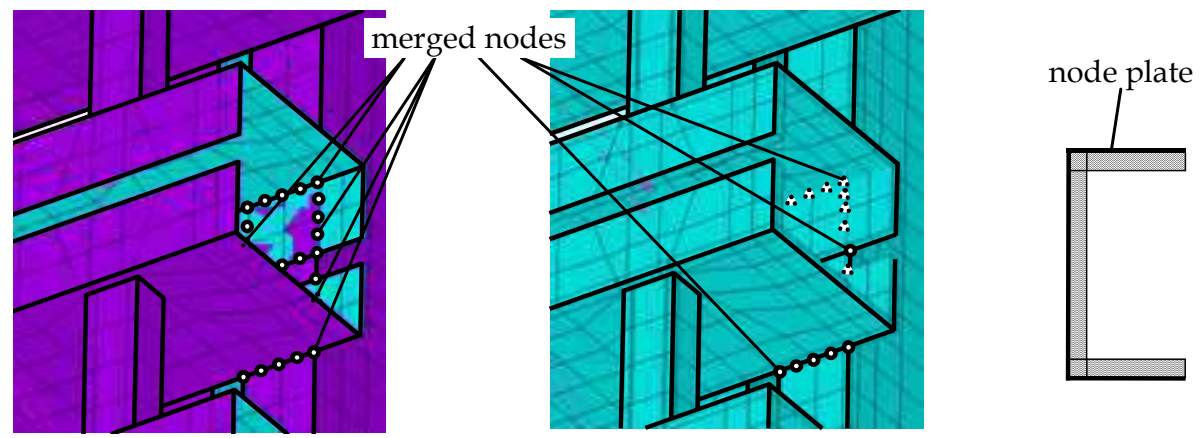

Fig. 4. Modelling of the welded joints

The first FE model is created in the following way: the base frame is modelled using shell elements (shell99) quadrilateral, eight nodes with six degrees of freedom on each node and the sets of channel sections of the base frame are modelled with shell99, assuming the location of the nodes on the external surface of the element (Fig. 4). However, this approach introduces a modelling error because of the excessive mass concentration in the corner of the channel sections, which results in improper inertia moments of the channel sections sets. The frame support was modelled assuming the constraint point wise in the areas where the frame is attached to the concrete foundation by the anchors. In each such point, one rotational degree of freedom along the axes of the anchor is left free (Fig. 5).

Additional reinforcement of the external sets of the channel sections in the upper layer is modelled by the beam element (beam44). Each of the rig assemblies together with corresponding steel tables (with the exception of supporting device) is modelled as a so called rigid region concentrated at the mass point where total mass is located. In the rigid region, two types of nodes can be distinguished: master nodes and slave nodes subordinated to the master node (Markowski et al., 2010). 


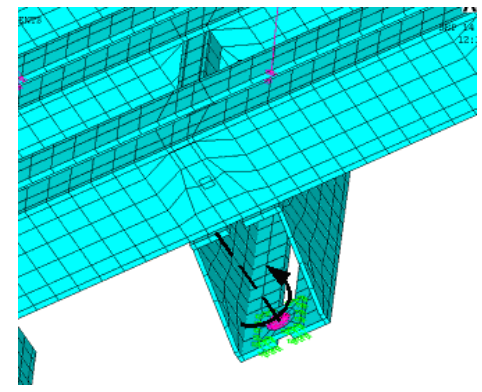

Fig. 5. The boundary condition

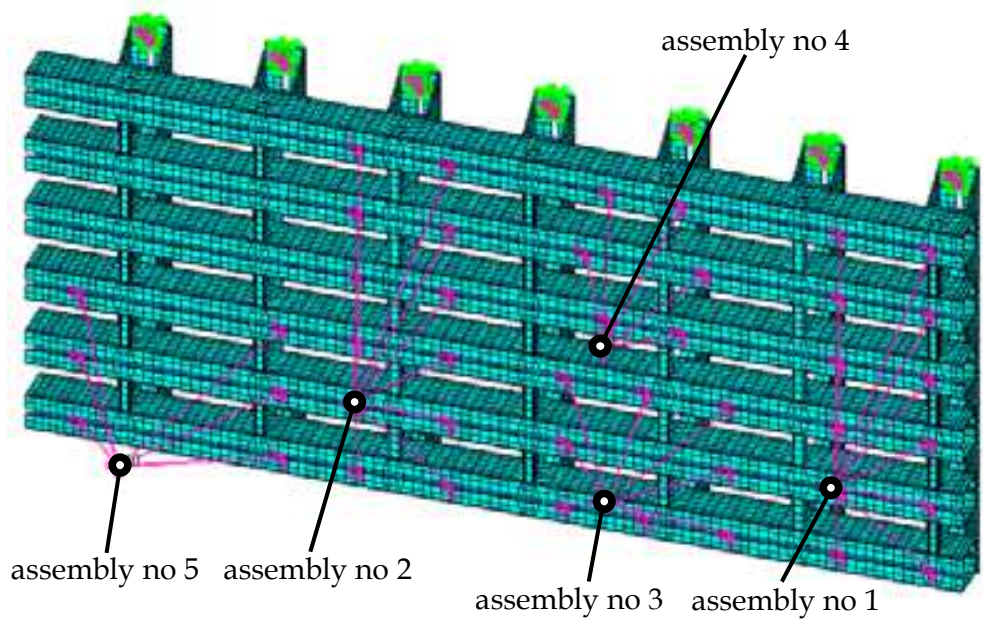

Fig. 6. First FE model of the system

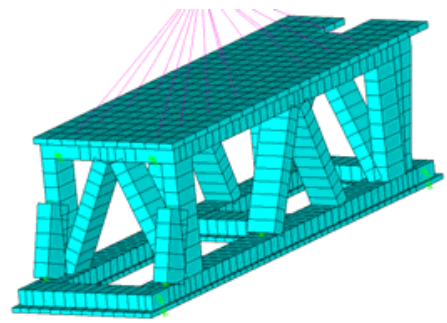

Fig. 7. Finite element model of the assembly no. 1 steel table

This means that slave nodes have the same DOF as the corresponding master node. With reference to the discussed rig, in all the applied rigid regions the location of the master nodes overlaps with the position of mass points located in the centre of gravity of modelled assemblies. Each mass point is realized by a single node mass element (mass21) with six DOF. The nodes of the base frame located in the collaboration regions of the modelled assemblies and modelled frame are considered the slave nodes of the particular rigid 
regions. The discussed FE model of the rig is presented in Fig. 6. The model contains 18208 shell elements (shell99), 19 mass point elements (mass21), 14 beam elements (beam44), and 56892 nodes. As was mentioned earlier, a model of the supporting device is not taken into consideration in this FE model.

In the second FE model case of the rig the base frame is modelled as in the previous case, but the modelling of the assemblies together with the corresponding steel tables are different. In this case the design features of the steel tables of the base frame and mutual connections between individual assemblies are considered. All of that creates a so - called power circulating rig. The bearing elements of each individual table are modelled by a beam element (beam44), whereas the steal plates are modelled by a shell element (shell99). The required connections and welded joints of each individual steal table component are realized by the node coupling method.

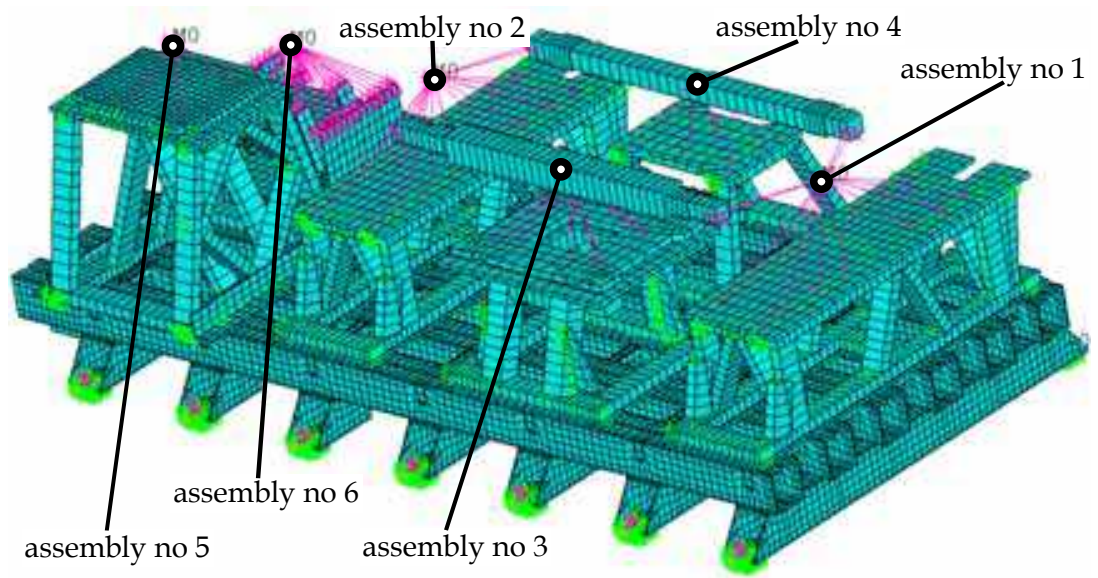

Fig. 8. Second FE model of the system

The assemblies seated on the tables are modelled as a mass point connected by a rigid region to the steel table. As in the previous case, each mass point (mass21) is located in the centre of the gravity modelled assembly. The rigid areas of the tables where the modelled assemblies are seated are considered to be the coupled sets of nodes ("slave" nodes). The connection of individual tables to the base frame is performed by the coupling function in the clamping areas. In Fig. 7 the table FE model with no. 1 assembly seated on it is presented. The shafts and the clutch assemblies in a power circulating rig are modelled by a beam element (beam44) and a spring element (combin14), and allow taking into account the elastic properties of the clutch. In the discussed model all important components of the analyzed rig are considered. The developed FE model of the rig consists of 20366 shell99 elements, 1625 beam44 elements, 28 mass 21 elements, 12 combine elements and 66026 nodes. The discussed model is shown in Fig. 8.

\subsection{Numerical calculations}

Numerical analysis results of natural frequencies of the gear fatigue test rig are obtained using the models presented earlier. For each approach, numerical calculations are conduced to evaluate natural frequencies of the system and corresponding mode shapes in the frequency range 0 to $300[\mathrm{~Hz}]$. For the steel elements used for the rig, the following data 
materials are used: Poisson ratio $v=0.3$, Young's modulus $E=2.1^{*} 10^{11}[\mathrm{~Pa}]$, and density $\rho=$ $7.86^{*} 10^{3}\left[\mathrm{~kg} / \mathrm{m}^{3}\right]$. The results are split into two categories. The natural frequencies and mode shapes related to the movement of assemblies mounted on the base frame are considered to be the first category. The other category includes the natural frequencies and mode shapes related to the local movement of the channel section sets of the base frame. The vibration of the assemblies with mode shapes, which could be considered the first category, have greater consequences for a proper rig operation because of their movement when the rig is running. The vibration of these particular assemblies can be realized as a concurrent oscillation form when the sense of movement has the same signs or a backward oscillation form when sense of movement has the opposite signs. For both FE models, numerical analysis results are presented with reference to the movements of the particular rig assemblies. In order to unambiguously describe the mode shapes presented, it is assumed that longitudinal movement is a movement in the plane parallel to the base and along the longer side of the base frame (Fig. 2). Transverse movement is a movement in the plane parallel to the base and along the shorter side of the base frame. The vertical movement is considered perpendicular to the base movement. For both FE models, the discussed results are presented in the sequence of appearance. At first the results generated from the first rig FE model are presented. The mass of the assemblies and the supporting tables (Fig. 6) required for the analysis is presented in Tab. 1.

\begin{tabular}{|c|c|c|c|c|c|}
\hline Assembly no. & 1 & 2 & 3 & 4 & 5 \\
\hline mass [kg] & 1480 & 1480 & 550 & 320 & 600 \\
\hline
\end{tabular}

Table 1. Evaluated mass of the particular assemblies of the test rig (first FE model)

The obtained natural frequency results and the description of related modes are included in Tab. 2. The graphic presentations of the discussed results are shown in Fig. 9 - 12.

\begin{tabular}{|c|c|c|c|}
\hline $\begin{array}{c}\text { Mode } \\
\text { no. }\end{array}$ & Mode shape description & $\begin{array}{c}\text { Value of the natural } \\
\text { frequency } \omega f[\mathrm{~Hz}]\end{array}$ & $\begin{array}{c}\text { Figure } \\
\text { no. }\end{array}$ \\
\hline P1 & Concurrent longitudinal vibration all assemblies & 22.068 & $9 \mathrm{a}$ \\
\hline P2 & Vertical vibration of the assembly no. 1 & 37.764 & $9 \mathrm{~b}$ \\
\hline P3 & $\begin{array}{c}\text { Backward vertical vibration of the assembly no. 1 } \\
\text { and 2 }\end{array}$ & 40.661 & $9 \mathrm{c}$ \\
\hline P4 & Concurrent transverse vibration all assemblies & 51.745 & $10 \mathrm{a}$ \\
\hline P5 & Vertical vibration of the assembly no. 5 & 57.672 & $10 \mathrm{~b}$ \\
\hline P6 & $\begin{array}{c}\text { Backward transverse vibration assemblies no. 1 } \\
\text { and 2 }\end{array}$ & 59.273 & $10 \mathrm{c}$ \\
\hline P7 & Vertical vibration of the assembly no. 3 & 73.346 & $11 \mathrm{a}$ \\
\hline P8 & Vertical vibration of the assembly no. 4 & 85.160 & $11 \mathrm{~b}$ \\
\hline P9 & $\begin{array}{c}\text { Concurrent transverse vibration assemblies no. 3 } \\
\text { and 4 and backward with assembly no. 5 }\end{array}$ & 93.031 & $11 \mathrm{c}$ \\
\hline P10 & $\begin{array}{c}\text { Concurrent vertical vibration of the assemblies no. } \\
\text { 3, 4 and 5 }\end{array}$ & 101.70 & $12 \mathrm{a}$ \\
\hline P13 & $\begin{array}{c}\text { Concurrent vertical - transverse vibration of the } \\
\text { assemblies no. 3 and 4. }\end{array}$ & 138.71 & $12 \mathrm{~b}$ \\
\hline
\end{tabular}

Table 2. Natural frequency and mode shapes of the test rig (first FE model) 
The values of the natural frequencies of the test rig corresponding to modes P3 - P10 are within the operating range of the rotating parts of the rig assemblies.
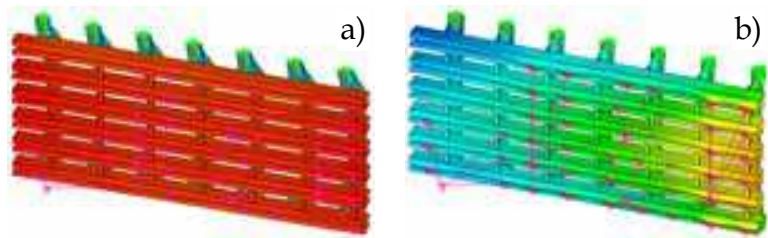

b)

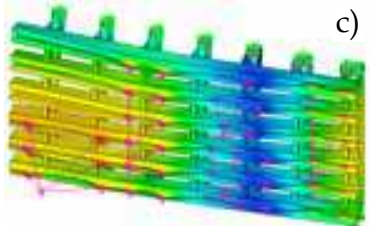

Fig. 9. Mode shapes: (a) P1, (b) P2, (c) P3
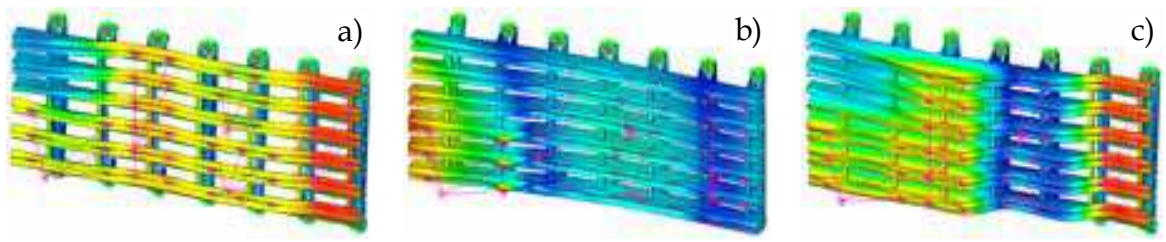

Fig. 10. Mode shapes: (a) P4, (b) P5, (c) P6
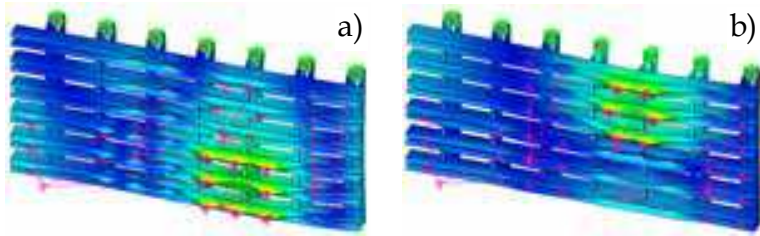

b)

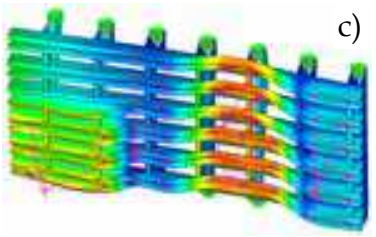

Fig. 11. Mode shapes: (a) P7, (b) P8, (c) P9

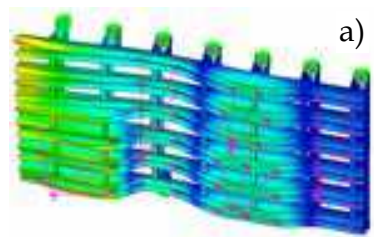

a)

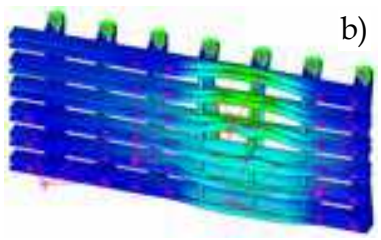

Fig. 12. Mode shapes: (a) P10, (b) P13

Subsequently the results of the second FE model of the rig are obtained as shown in Fig. 8 . As mentioned before the design features of the tables located under the assemblies of the rig and the connections between the individual assemblies are taken under consideration, and those created as so - called a power circulating rig that creates a so - called a power circulating rig. Included in the calculations are the estimated masses of particular assemblies shown in Fig. 8, which are modelled by rigid, which mass are value presented in Tab. 3.

\begin{tabular}{|c|c|c|c|c|c|c|}
\hline Assembly no. & 1 & 2 & 3 & 4 & 5 & 6 \\
\hline mass [kg] & 1100 & 1200 & 350 & 150 & 290 & 320 \\
\hline
\end{tabular}

Table 3. Evaluated mass of the particular assemblies of the test rig (second FE model) 
The received frequencies with their corresponding description are shown in Tab. $4 a-b$. Figs. 13 - 20 presents the discussed mode shapes.

As expected, based on the second FE model of the rig, a greater number of natural frequencies and corresponding modes are received in comparisons to the first FE model. Moreover the consideration of the design features of the tables allowed for more accurate results pertaining to the range of form of particular natural frequencies. The values of the natural frequencies of the rig corresponding to modes D5 - D19 are within the operating range of the rotating parts of the rig assemblies. From the analysis of the received vibration forms it can be concluded that the tables seated on the base frame supporting assemblies are practically not subjected to deformation (they are characterized by higher stiffness in relation to the base frame). Some part of the received results is characterized by a qualitative similarity to the majority of the solutions received from the first rig FE model. A qualitative similarity between forms D2 and P1, D4 and P2, D5 and P3, D6 and P4, D10 and P6, D16 and P7, D18 and P8, D24 and P13 can be observed. A similarity to the solution from the second model is not observed for forms P5, P9, P10 from the first FE model.

\begin{tabular}{|c|c|c|c|}
\hline $\begin{array}{l}\text { Mode } \\
\text { no. }\end{array}$ & Mode shape description & $\begin{array}{l}\text { Value of the natural } \\
\text { frequency } \omega f[\mathrm{~Hz}]\end{array}$ & $\begin{array}{l}\text { Figure } \\
\text { no. }\end{array}$ \\
\hline D1 & Longitudinal vibration of the assembly no. 6 & 14.01 & $13 a$ \\
\hline D2 & Concurrent longitudinal vibration all assemblies & 21.07 & $13 b$ \\
\hline D3 & Vertical vibration of the assembly no. 6 & 23.15 & $13 c$ \\
\hline D4 & $\begin{array}{l}\text { Concurrent vertical vibration of all assemblies } \\
\text { besides assembly no. } 6 \text {. Additionally swinging } \\
\text { transverse backward motion assemblies no. } 3 \text { and } \\
4\end{array}$ & 38.49 & $14 a$ \\
\hline D5 & $\begin{array}{l}\text { Swinging longitudinal motion of assembly no. } 4 \\
\text { and vertical backward vibration of assembly no. } 1 \\
\text { against assembly no. } 2 \text { and } 5\end{array}$ & 41.21 & $14 b$ \\
\hline D6 & $\begin{array}{c}\text { Transverse concurrent vibration all assemblies and } \\
\text { vertical backward vibration of assembly no. } 1 \\
\text { against assembly no. } 2 \text { and } 5\end{array}$ & 41.52 & $14 \mathrm{c}$ \\
\hline D7 & $\begin{array}{l}\text { Swinging longitudinal motion of assembly no. } 4 \\
\text { and vertical backward vibration of assembly no. } 1 \\
\text { and } 6 \text { against assembly no. } 2 \text { and } 5\end{array}$ & 43.77 & $15 a$ \\
\hline D8 & $\begin{array}{c}\text { Transverse backward vibration of assembly no. 1, } 4 \\
\text { and } 3 \text { against assembly no. 2, } 5 \text { and } 6\end{array}$ & 45.65 & $15 b$ \\
\hline D9 & $\begin{array}{l}\text { Swinging longitudinal motion of assembly no. } 4 \\
\text { and } 5 \text {, backward vibration of assembly no. 1, } 2 \text { and } \\
3\end{array}$ & 48.53 & $15 c$ \\
\hline
\end{tabular}

Table 4a. Natural frequency and mode shapes of the test rig (second FE model) 


\begin{tabular}{|c|c|c|c|}
\hline $\begin{array}{l}\text { Mode } \\
\text { no. }\end{array}$ & Mode shape description & $\begin{array}{l}\text { Value of the } \\
\text { natural } \\
\text { frequency } \omega f \\
{[\mathrm{~Hz}]}\end{array}$ & $\begin{array}{l}\text { Figure } \\
\text { no. }\end{array}$ \\
\hline D10 & $\begin{array}{l}\text { Transverse backward vibration of assembly no. } 1,5 \\
\text { against assembly no. } 2,3 \text { and } 4\end{array}$ & 52.42 & $16 a$ \\
\hline D11 & $\begin{array}{l}\text { Swinging transverse backward motion of assemblies no. } \\
3 \text { and } 4 \text { and longitudinal vibration of assembly no. } 5\end{array}$ & 54.34 & $16 b$ \\
\hline D12 & $\begin{array}{c}\text { Transverse backward vibration of assembly no. } 1 \text { and } 2 \\
\text { against assemblies no. 3, } 4 \text { and } 5\end{array}$ & 55.91 & $16 \mathrm{c}$ \\
\hline D13 & $\begin{array}{l}\text { Swinging longitudinal vibration of assembly no. } 5 \text { and } \\
\text { transverse motion of the assembly no. } 4\end{array}$ & 59.35 & $17 \mathrm{a}$ \\
\hline D14 & $\begin{array}{c}\text { Dominant swinging transverse motion of assembly no. } \\
3 \text { and transverse vibration of assembly no. } 6\end{array}$ & 68.78 & $17 \mathrm{~b}$ \\
\hline D15 & $\begin{array}{l}\text { Transverse vibration of assembly no. } 6 \text {, and swinging } \\
\text { motion of assembly no. } 3\end{array}$ & 69.46 & $17 \mathrm{c}$ \\
\hline D16 & $\begin{array}{c}\text { Vertical backward vibration of assemblies no. } 3 \text { and } 5 \\
\text { against assemblies no. } 1 \text { and } 2\end{array}$ & 71.26 & $18 \mathrm{a}$ \\
\hline D17 & $\begin{array}{l}\text { Vertical backward vibration of assemblies no. } 3 \text { and } 5 \\
\text { and longitudinal backward vibration of assemblies no. } 1 \\
\text { and } 2\end{array}$ & 79.69 & $18 b$ \\
\hline D18 & Vertical vibration of assembly no. 4 & 94.84 & $18 \mathrm{c}$ \\
\hline D19 & $\begin{array}{l}\text { Vertical vibration of the base frame under assembly no. } \\
6\end{array}$ & 112.78 & $19 \mathrm{a}$ \\
\hline D20 & $\begin{array}{l}\text { Longitudinal concurrent vibration all assemblies } \\
\text { (second form, mass points are immovable) }\end{array}$ & 129.12 & $19 b$ \\
\hline D24 & $\begin{array}{c}\text { Transverse vibration of the base frame under assemblies } \\
\text { no. } 3 \text { and } 4 \text { (mass points are motionless) }\end{array}$ & 155.83 & $19 \mathrm{c}$ \\
\hline D31 & $\begin{array}{l}\text { Transverse vibration of the base frame under assemblies } \\
\text { no. } 5 \text { and } 6\end{array}$ & 165.85 & 20 \\
\hline
\end{tabular}

Table 4b.Natural frequency and mode shapes of the test rig (second FE model)
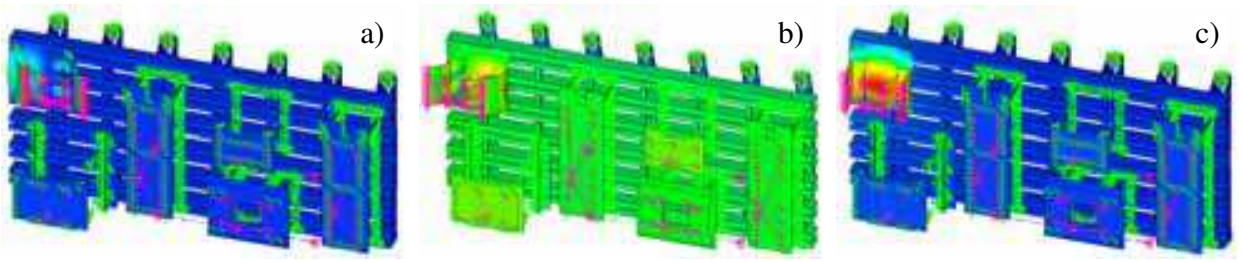

Fig. 13. Mode shapes: (a) D1, (b) D2, (c) D3 

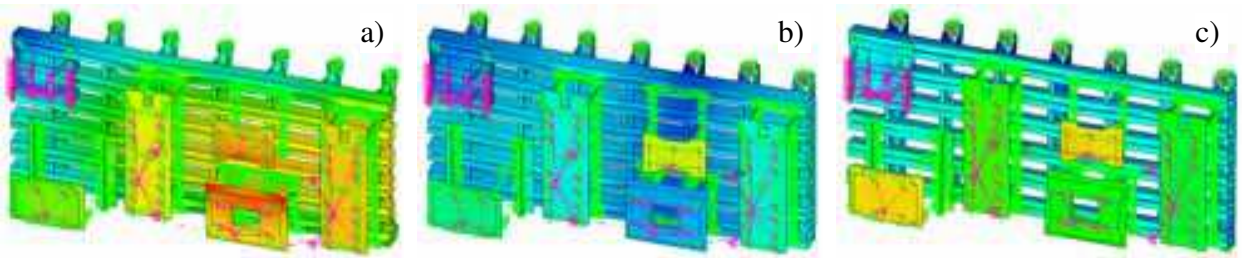

Fig. 14. Mode shapes: (a) D4, (b) D5, (c) D6
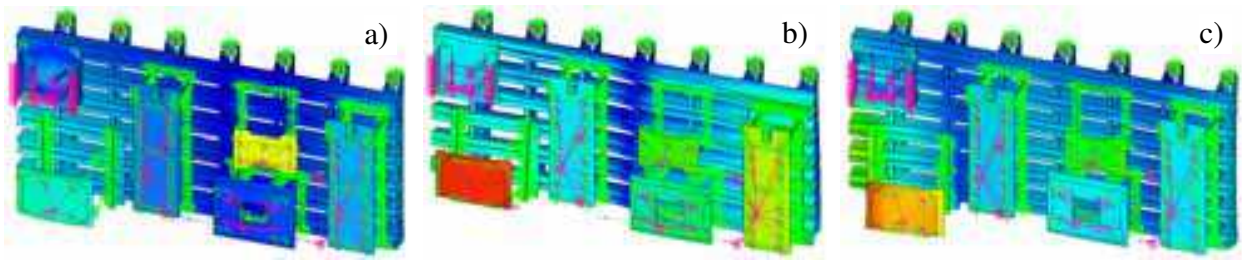

Fig. 15. Mode shapes: (a) D7, (b) D8, (c) D9
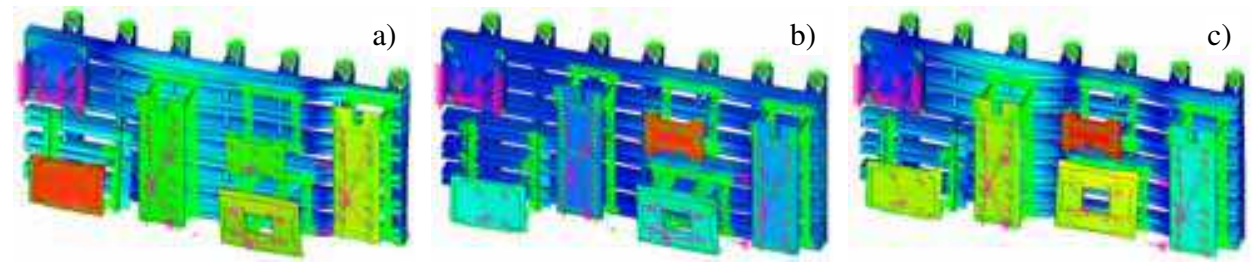

Fig. 16. Mode shapes: (a) D10, (b) D11, (c) D12
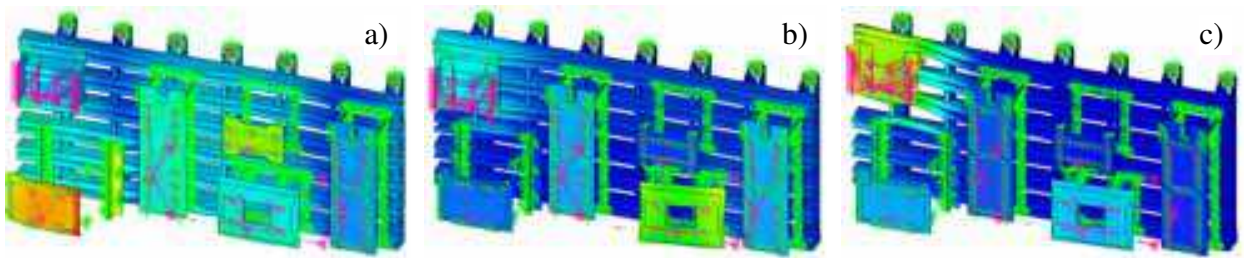

Fig. 17. Mode shapes: (a) D13, (b) D14, (c) D15
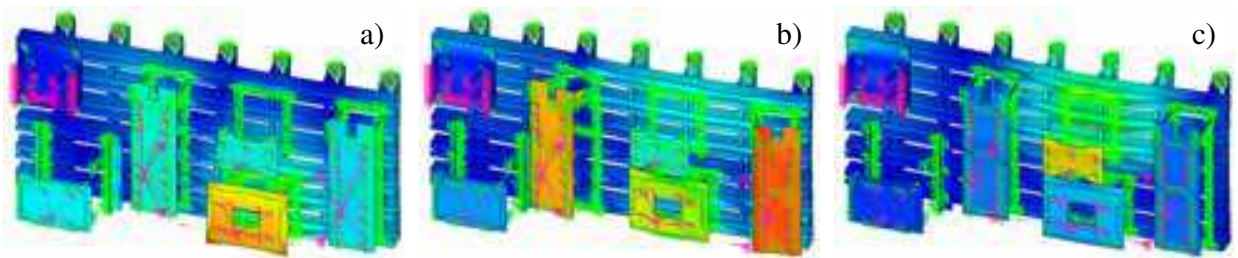

Fig. 18. Mode shapes: (a) D16, (b) D17, (c) D18 

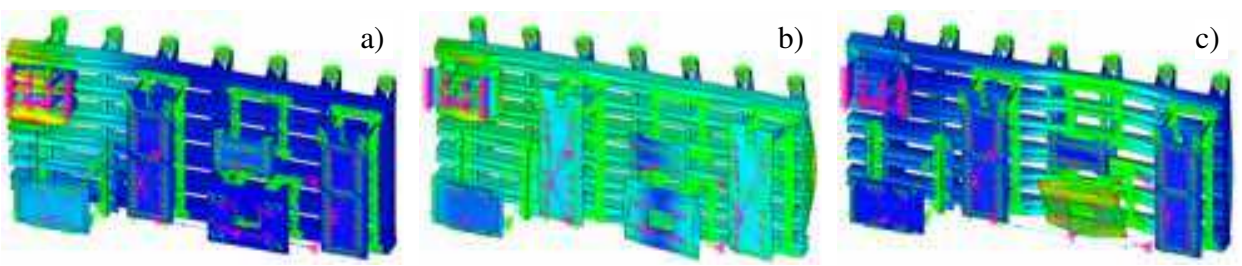

Fig. 19. Mode shapes: (a) D19, (b) D20, (c) D24

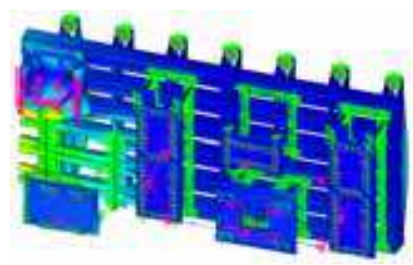

Fig. 20. Mode shape D31

\subsection{Experimental investigations}

The prepared FE models of the test rig are verified by the experimental investigation on a real object (Fig. 3). A Brüel and Kjær measuring set is used in the experimental investigation.

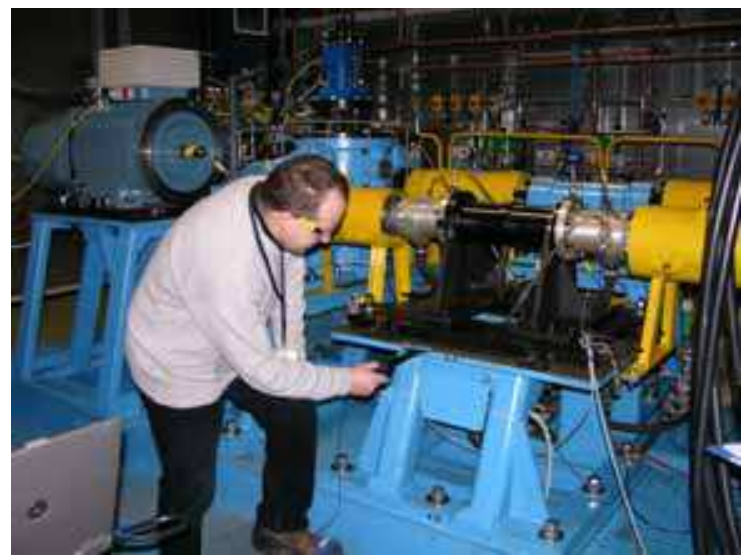

Fig. 21. The measuring test

The set consisted of the 8202 type modal hammer equipped with a gauging point made of a composite material, the 4384 model of accelerometer, the analogue signal conditioning system, the acquisition system, and the data processing system supported by Lab View analytical software. The analysis of the results of the experimental investigation is conducted on a portable computer using actual measured values. The measurement experiment is scheduled and conducted to identify natural frequencies and corresponding mode shapes related to the transverse, longitudinal and vertical vibration of the assemblies no. 1 and 2, respectively. Because only one accelerometer was accessible, the measurement 
process is conducted in a so - called measurement group. For each group, the accelerometer position for a tap place point for the hammer (impulse excitation) is established.

When the location of the measurement points for a particular group was to be determined a numerical calculation was used as reference. The experiments are planned and conducted for five measurement groups. The first group is made up of points 1 to 6 , and is located on the base frame and table no. 1 (Fig. 22). The accelerometer is located in point no. 2. The second group consists of points 7, 8, 9, 10 and 14, and is located on the table of assemblies no. 1, 2, 3 and 5 (Fig. 22 and 23).

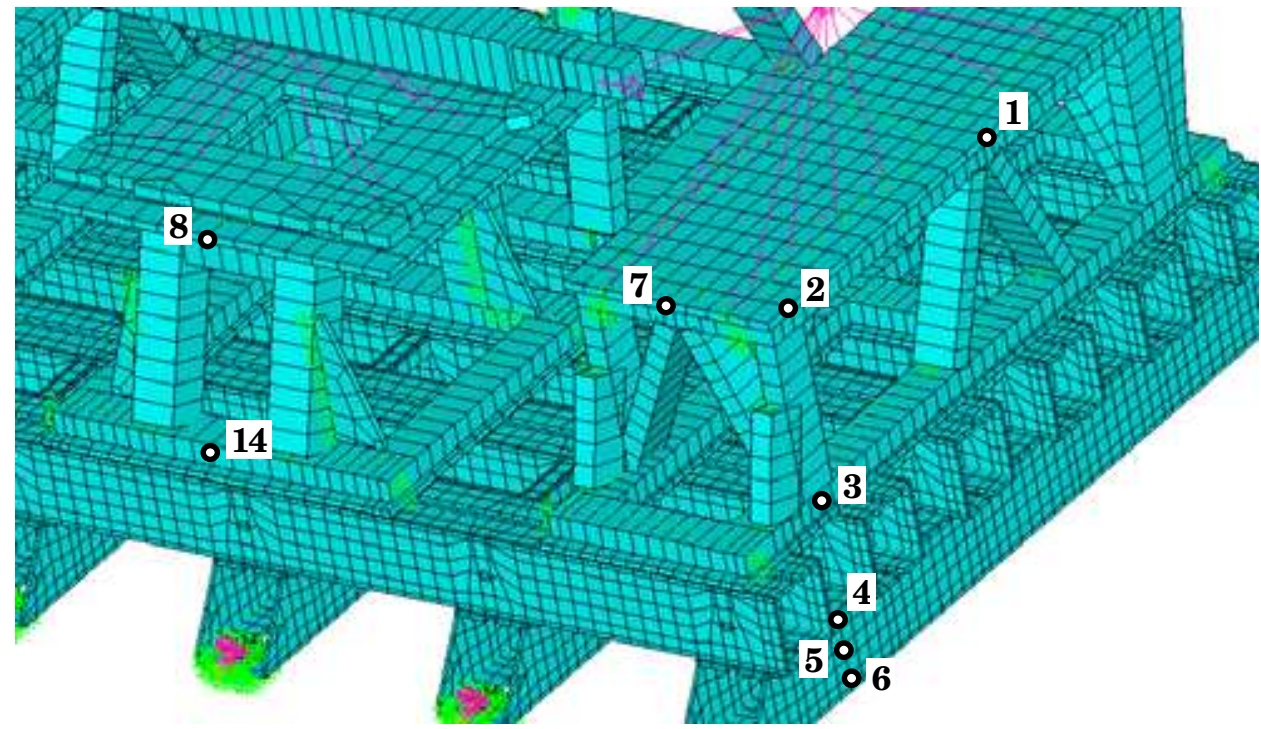

Fig. 22. Measuring set points

\begin{tabular}{|c|c|c|c|}
\hline Mode no. & $\begin{array}{c}\text { Measuring set } \\
\text { no. }\end{array}$ & $\begin{array}{c}\text { Measured natural frequency } \\
\text { value } \omega^{e}[\mathrm{~Hz}]\end{array}$ & $\begin{array}{c}\text { Frequency relative error } \\
\varepsilon[\%]\end{array}$ \\
\hline P1 & 1,4 & 27.77 & -20.5 \\
\hline P2 & 1 & 38.15 & -1.01 \\
\hline P4 & 2 & 46.70 & 10.8 \\
\hline P7 & 2 & 73.24 & 0.15 \\
\hline
\end{tabular}

Table 5. Experimental investigation results related to the first FE model

The accelerometer for this group is located in point no. 8. The third measurement group is made up of points no. 10 and 11 (Fig. 23), while the experiment is conducted the accelerometer is located in point no. 10 and subsequently in point no. 11. The fourth measurement point is made of points 13 and 15, and the accelerometer is located in point no. 13 (Fig. 23). The fifth group consists of points 12 and 16, where the accelerometer was located in point 12. For all the discussed cases the impulse response is registered which 
caused modal hammer vibrations in each of the mentioned points. Tables 5 and 6 present the natural frequencies excited and identified in the measurement experiment, their corresponding mode shapes, and frequency error defined according to formula (4).

The results presented in Tab. 5 refer to the first FE model of the system, whereas the results for the second FE model are shown in Tab. 6.

Identification of the form is conducted by a qualitative comparison of the numerical and experimental results. In Fig. 24, the frequency characteristic of the system for the first measured group is presented. Fig. 24a presents the amplitude - phase characteristic, whereas Fig. $24 \mathrm{~b}$ presents the phase - frequency characteristic.

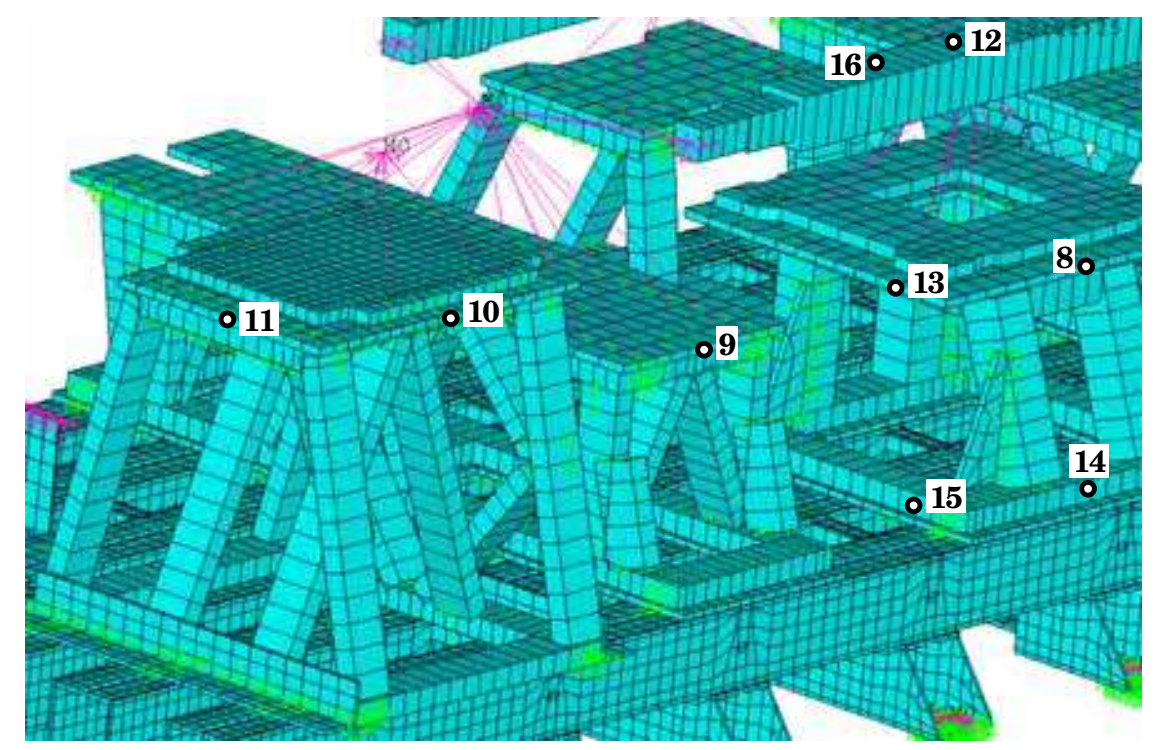

Fig. 23. Measuring set points

\begin{tabular}{|c|c|c|c|}
\hline Mode no. & $\begin{array}{c}\text { Measuring set } \\
\text { no. }\end{array}$ & $\begin{array}{c}\text { Measured natural frequency } \\
\text { value } \omega^{e}[\mathrm{~Hz}]\end{array}$ & $\begin{array}{c}\text { Frequency relative error } \\
\varepsilon[\%]\end{array}$ \\
\hline D2 & 1,4 & 27.77 & -24.1 \\
\hline D4 & 1 & 38.15 & 0.9 \\
\hline D6 & 2 & 46.70 & -11.1 \\
\hline D9 & 1 & 50.05 & -3.0 \\
& 3 & 50.35 & -3.6 \\
\hline D11 & 2 & 55.85 & -2.7 \\
& 3 & 56.15 & -3.2 \\
\hline D13 & 5 & 61.34 & -3.2 \\
\hline D14 & 4 & 65.30 & 5.3 \\
\hline D16 & 2 & 73.24 & -2.7 \\
\hline D24 & 2 & 153.20 & 1.7 \\
\hline
\end{tabular}

Table 6. Experimental investigation results related to the second FE model 
When analyzing the received results (Tab. 5 and 6), a small difference can be observed in both cases between the numerical results and the experiment related to the frequencies connected with the vertical vibration (forms P2 and P7 of the first FE model and D4 and D16 of the second one). A relatively small difference can be observed for natural frequencies related to the complex forms of vibration where there is a combination of vertical and transverse vibration or transverse vibration of the assemblies no. 3 and 4 (forms D9, D11, D13, D14, D16 and D24 of the second FE model). For both models significant differences occur for the natural frequencies connected to the concurrent vibrations in the base frame plane of the rig (forms P1 and P4 of the first FE model and forms D2 and D6 of the second FE model).
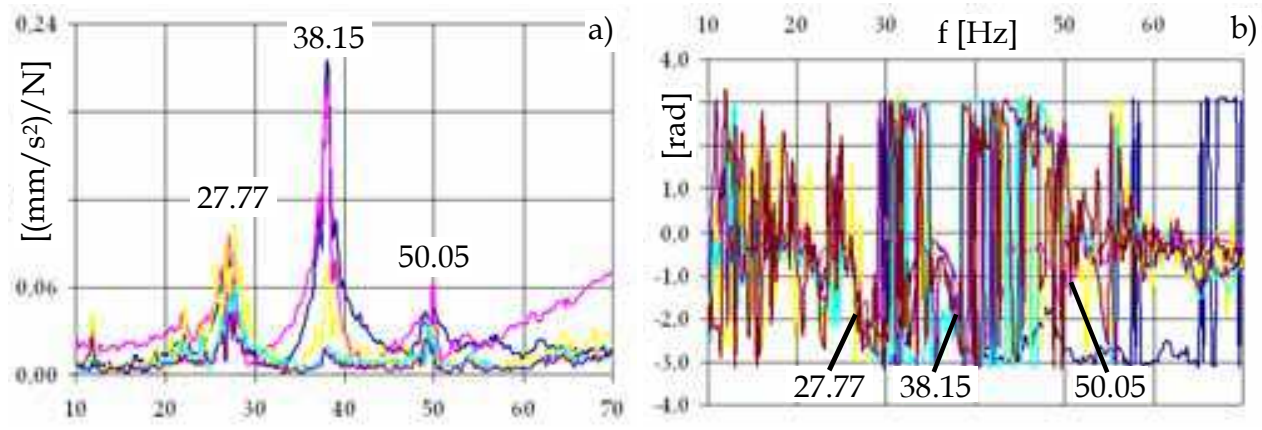

Fig. 24. Frequency characteristic of the system

\section{Vibration of the aviation engine turbine blade}

In this section, the free vibration of an aviation engine turbine blade is analyzed. Rudy (Rudy \& Kowalski, 1998) presents the introductory studies connected with the discussed problem. In the elaborated blade FE models a complex geometrical shape and the manner of the blade attachment to the disk are taken into consideration. Some numerical results are verified by the measurement experiment.

\subsection{Free vibration of the engine turbine blades}

Gas turbine blades are one of the most important parts among all engine parts. Those elements are characterized by complex geometry and variations of material properties connected with temperature. Moreover, it is necessary to take into account the manner of the blade attachment to the disk. The most popular is fixing by a so - called fir tree. During operation the blade vibrates in different directions. To facilitate consideration circumferential, axial and torsional vibration are distinguished but as a matter of fact circumferential and axial vibration are bending. In fact all mentioned vibrations are a compound of torsional and bending vibrations. Each vibrating continuous system is described by unlimited degrees of freedom and consequently unlimited number of natural frequencies. The blade vibration with the lowest value is called the first order tangential mode. For the analytical calculation of natural frequencies of a blade, the usual assumption is that of the Euler - Bernoulli model of the beam (Łączkowski, 1974) with constant cross - section fixed in one end. There is significant variability of geometrical parameters long ways of the blade. In accordance with the mentioned approach, for the blade with geometrical parameters at the bottomsection, the 
natural frequency is equal to $1189.2[\mathrm{~Hz}]$ and for geometrical parameters of the midspan of the blade the natural frequency is equal to $931.6[\mathrm{~Hz}]$. To achieve more accurate results, the more precise model which takes into account the variability of blade geometry and the manner of the blade fixing to the disk, needs to be prepared.

\subsection{Conception of the engine turbine blade finite element formulation}

The prepared FE model consists of a sector of the disk with the blade. To decrease the complexity of the model, a sector of the disk with an angle resulting from the number of assembled blades is limited to a specific radius at the bottom side. The blade and the disk sector are modeled with the use of solid elements. In most cases hexahedral elements are used, however, the model consists of wedge and tetrahedral elements as well. In the analyzed case, blades are attached to the disk by a fir tree with three lobes. The collaboration regions of the blade and the sector disk are modelled by using the 3D contact elements. Those elements allow taking into account the relative displacement of the faces in contact under the influence of an external load. A slip soft contact element is used with a friction coefficient equal 0.1. Because the prepared model includes only the circular sector of the disk, it is necessary to apply cyclic symmetry boundary conditions. Moreover, because the disk is limited to a specific internal diameter it is necessary to apply a proper DR displacement to model the removed part of the disk. The DR value is initially calculated using an axisymmetrical model where blade load was modelled as uniform pressure on the rim of the disk.

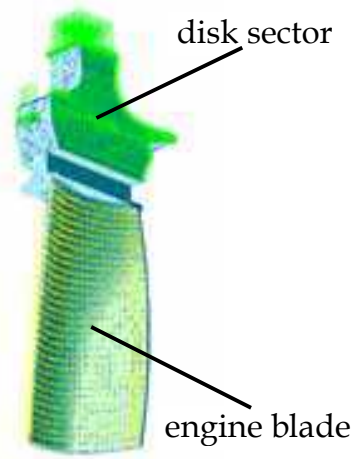

Fig. 25. Finite element model of the system

The discussed FE model of the blade with the sector disk is shown in Fig. 25. The blade is modelled by using 7986 solid elements and it has 10155 nodes. The disk sector is modelled by using 9646 solid elements with 12056 nodes. The contact region include 210 3D contact elements. The FE model in question is performed in MSC/PATRAN system, whereas dynamic analysis is performed in MSC/ADVANCED_FEA solver.

\subsection{Numerical calculations}

Numerical analysis of the engine turbine blade with the disk sector free vibration is obtained using the model suggested earlier. For each approach, only the first nine natural frequencies 
and mode shapes are evaluated. For the blade, the following data materials are used: Poisson ratio $v=0.3$, Young's modulus $E=2.1^{*} 10^{11}[\mathrm{~Pa}]$, and density $\rho=8.2^{*} 10^{3}\left[\mathrm{~kg} / \mathrm{m}^{3}\right]$. Specially, the impact of the manner of the blade fixing to the disk in the FE models on the value of the natural frequencies of the blade is analyzed. At first, analysis for nominal dimensions of the fir tree is performed (the load is distributed uniformly on each lobe). Then, two extreme cases are chosen, where lobes are made in such a way that the top lobes are loaded more in one case and the bottom lobes in another. Tolerance limit for analysis is assumed at the level of 0.02 [mm]. The forces generated the lobes loading derive from the centrifugal forces arisen within blade during its rotation. For these cases the calculation are executed assuming that the systems rotate with the rotational speed equal to 15100 [rpm].

For the next analyzed instance the natural frequencies of the engine blade without the disk sector are computed. It is assumed that the blade is fixed on contact faces of the lobe and the rotational speed is equal to $0,7550[\mathrm{rpm}]$ and 15100 [rpm], respectively. Frequency results for such models are presented in Table 7.

\begin{tabular}{|c|c|c|c|c|c|c|}
\hline \multirow{2}{*}{$\begin{array}{c}\text { Mode } \\
\text { no. }\end{array}$} & \multicolumn{6}{|c|}{ Value of the natural frequency $\omega f[\mathrm{~Hz}]$} \\
\cline { 2 - 7 } & \multicolumn{2}{|c|}{ Blade without the disk sector } & \multicolumn{3}{|c|}{ Blade with the disk sector } \\
\cline { 2 - 7 } & $\begin{array}{c}0 \\
{[\mathrm{rpm}]}\end{array}$ & $\begin{array}{c}7550 \\
{[\mathrm{rpm}]}\end{array}$ & $\begin{array}{c}15100 \\
{[\mathrm{rpm}]}\end{array}$ & $\begin{array}{c}\text { Nom. dim. of } \\
\text { fir tree }\end{array}$ & $\begin{array}{c}\text { Top lobe more } \\
\text { loaded }\end{array}$ & $\begin{array}{c}\text { Bottom lobe } \\
\text { more loaded }\end{array}$ \\
\hline 1 & 1134.0 & 1177.2 & 1260.6 & 1124.8 & 1141.4 & 1069.7 \\
\hline 2 & 2251.9 & 2290.2 & 2320.0 & 1629.3 & 1635.7 & 1603.3 \\
\hline 3 & 3705.0 & 3720.5 & 3636.4 & 2524.0 & 2533.1 & 2495.0 \\
\hline 4 & 5182.0 & 5230.0 & 5184.8 & 4021.1 & 4067.3 & 3871.6 \\
\hline 5 & 6510.0 & 6530.4 & 6361.3 & 5412.8 & 5476.6 & 5238.5 \\
\hline 6 & 9218.0 & 9256.5 & 9031.5 & 7548.4 & 7598.3 & 7332.1 \\
\hline 7 & 9945.9 & 9969.7 & 9689.1 & 8782.1 & 8863.5 & 8379.8 \\
\hline 8 & 11125 & 11170 & 10906 & 9633.2 & 9709.6 & 9277.1 \\
\hline 9 & 14174 & 14217 & 13827 & 9846.8 & 10046 & 9672.0 \\
\hline
\end{tabular}

Table 7. Natural frequencies of the system under study

First three mode shapes of vibration corresponding to the presented pairs of the natural frequencies are presented in Fig. 26.

a)

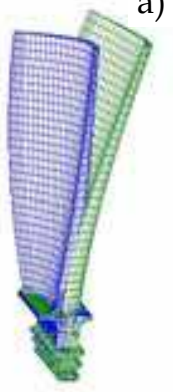

b)

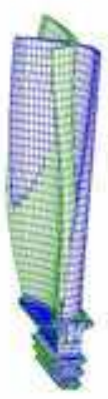

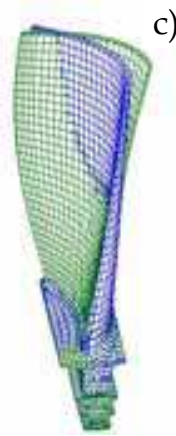

c)

Fig. 26. Mode shapes: (a) no. 1, (b) no. 2, (c) no. 3 
It can be seen that performing the lobes on the blade and disk have an influence on the value of blade natural frequencies. For example when the top lobe of the fir tree is more loaded, the first natural frequency increases by 1.5 [\%] while in the case that the bottom lobe is more loaded, frequency decreases by 4,9 [\%] in comparison to the nominal blade configuration. In the instance where the blade is fixed on contact faces of the lobe, the natural frequencies are higher as in the case of the blade with the disk sector. For example, natural frequencies for 1 , 2 and 3 form increase correspondingly by 12,1 [\%], 42,4 [\%] and 44,1 [\%] in relation to blade with the disk sector with nominal configuration.

Usually, endurance tests of blades are conducted on a shaker table. Such experimental investigations are useful for verification the proposed FE model of the blade. The blade is mounted in fixing part of the circular section of the disk and it is excited with the range of frequency $1020-1120$ [Hz], which refers to the first natural frequencies. A bit lower few percent value of natural frequency received during the test is as a result of flexibility of the fixture seated on the shaker.

\section{Vibration of the annular membrane resting on an elastic Winkler - type foundation}

In this section, the free transversal vibration of the annular membrane attached to a Winkler foundation is studied using analytical methods and numerical simulation. The introductory studies related to this problem are presented by Noga (Noga, 2010b). At first the general solution of the free vibration problem is derived by the Bernoulli - Fourier method. The second model is formulated by using finite element representations. The results received from the analytical solution (natural frequencies and its mode shapes) allow the determination of the quality of the developed FE models.

\subsection{Theoretical formulation}

The mechanical model of the system under study consists of an annular membrane resting on a massless, linear, elastic foundation of a Winkler type. It is assumed that the membrane is thin, homogeneous and perfectly elastic, and it has constant thickness. The membrane is uniformly stressed by adequate constant tensions applied at the edges (Fig. 27).

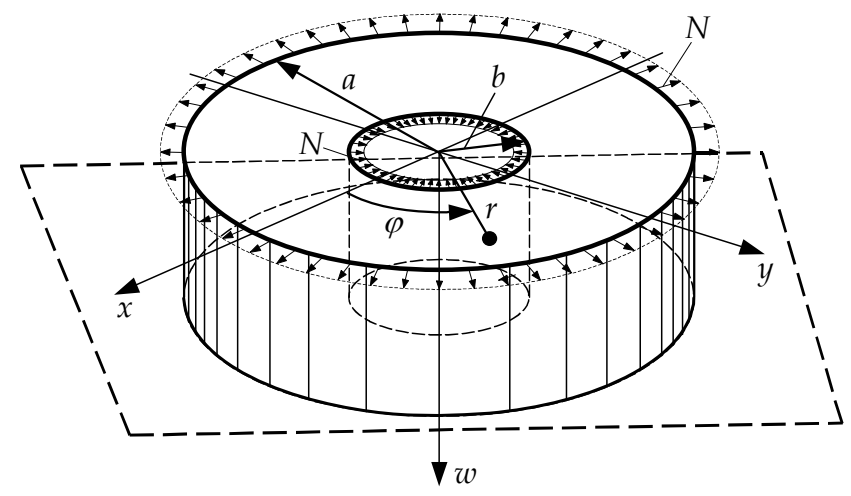

Fig. 27. Vibrating system under study 
Making use of the classical theory of vibrating membranes, the partial differential equations of motion for the free transversal vibrations are

$$
m_{D} \ddot{w}-N \Delta w+k w=0
$$

where $w=w(r, \varphi, t)$ is the transverse membrane displacement, $r, \varphi, t$ are the polar coordinates and the time, $a, b, h$ are the membrane dimensions, $\rho$ is the mass density, $N$ is the uniform constant tension per unit length, $k$ is the stiffness modulus of a Winkler elastic foundation and

$$
m_{D}=\rho h, \quad \dot{w}=\frac{\partial w}{\partial t}, \quad \Delta w=\frac{\partial^{2} w}{\partial r^{2}}+\frac{1}{r} \frac{\partial w}{\partial r}+\frac{1}{r^{2}} \frac{\partial^{2} w}{\partial \varphi^{2}}
$$

The boundary and periodicity conditions are

$$
w(a, \varphi, t)=w(b, \varphi, t)=0, \quad w(r, \varphi, t)=w(r, \varphi+2 \pi, t)
$$

Now using the separation of variables method (Kaliski 1966), one writes

$$
w(r, \varphi, t)=W(r, \varphi) T(t), \quad T(t)=C \sin (\omega t)+D \cos (\omega t)
$$

where $\omega$ is the natural frequency of the system. Introducing solutions (8) into (5) gives the following expression

$$
\Delta W+k_{D}^{2} W=0, \quad k_{D}^{2}=\left(m_{D} \omega^{2}-k\right) / N
$$

The coefficient $k_{D}^{2}$ is positive when $\omega^{2}>k / m_{D}$. This condition guarantees harmonic free vibrations (Noga 2010). The solution of equation (9) is assumed in the form

$$
W(r, \varphi)=R(r) U(\varphi)
$$

The boundary and periodicity conditions in terms of $R(r)$ and $U(\varphi)$ become

$$
R(a)=R(b)=0, \quad U(\varphi)=U(\varphi+2 \pi)
$$

Substituting solution (10) into (9) yields

$$
R_{n}(r)=A_{n} J_{n}\left(k_{D} r\right)+B_{n} Y_{n}\left(k_{D} r\right), U_{n}(\varphi)=L_{n} \sin (n \varphi)+M_{n} \cos (n \varphi), n=0,1,2, \ldots
$$

where $A_{n}, B_{n}, L_{n}, M_{n}$ are unknown coefficients and $J_{n}(\cdot)$, and $Y(\cdot)$ are the first and second kinds of Bessel functions of order $n$. Conditions (11) yields a system of two linear, homogeneous equations in the constants $A_{n}, B_{n}$. Finally, a determinant gives the equation for the natural frequencies from the non - triviality condition. It yields the secular equation

$$
J_{n}\left(k_{D} a\right) Y_{n}\left(k_{D} b\right)-J_{n}\left(k_{D} b\right) Y_{n}\left(k_{D} a\right)=0
$$


From the relation (13) it is proved that $k_{D}=k_{m n}(m=1,2,3, \ldots)$ are the roots of the above equation. Then taking into account equation (9), the natural frequencies of the system under consideration are determined from the relation

$$
\omega^{2}=\omega_{m n}^{2}=\left(k_{m n}^{2} N+k\right) / m_{D}
$$

The general solution of the free vibrations of the system under study takes the form

$$
\begin{gathered}
w(r, \varphi, t)=\sum_{m=1}^{\infty} \sum_{n=0}^{\infty} W_{m n}(r, \varphi) T_{m n}(t)=\sum_{m=1}^{\infty} \sum_{n=0}^{\infty}\left(\left(C_{m n}^{(1)} \sin \left(\omega_{m n} t\right)+D_{m n}^{(1)} \cos \left(\omega_{m n} t\right)\right) \times\right. \\
\left.\times W_{m n}^{(1)}(r, \varphi)+\left(C_{m n}^{(2)} \sin \left(\omega_{m n} t\right)+D_{m n}^{(2)} \cos \left(\omega_{m n} t\right)\right) W_{m n}^{(2)}(r, \varphi)\right)
\end{gathered}
$$

where

$$
\begin{aligned}
& W_{m n}^{(1)}(r, \varphi)=\left(e_{m n} J_{n}\left(k_{m n} r\right)+Y_{n}\left(k_{m n} r\right)\right) \sin (n \varphi) \\
& W_{m n}^{(2)}(r, \varphi)=\left(e_{m n} J_{n}\left(k_{m n} r\right)+Y_{n}\left(k_{m n} r\right)\right) \cos (n \varphi)
\end{aligned}
$$

are two linear - independent mode shapes, and

$$
e_{m n}=-Y_{n}\left(k_{m n} a\right) / J_{n}\left(k_{m n} a\right)
$$

\subsection{Finite element representations}

Finite element models are formulated to discretize the continuous model given by equation (5). As mentioned earlier, the FE models are treated as an approximation of the exact system. The quality of the approximate model depends on the type and density of the mesh. The essential problem of this section is building the FE model of the elastic foundation. The two FE models with different realizations of the Winkler elastic foundation are prepared and discussed by using ANSYS FE code. The first FE model is realized as follows. The foundation is modeled by a finite number of parallel massless springs. The stiffnes modulus $k_{S}$ of each spring can be obtained from the relation (Noga, 2010a)

$$
k_{S}=\left(k p_{0}\right) / b
$$

where $p_{0}$ is the area of the membrane large face and $b$ is the number of the springs. The spring - damper element (combin14) defined by two nodes with the option " 3 - D option longitudinal" is used to realize the elastic foundation. The damping of the element is omitted. The layer consists of 9324 combin elements. The annular membrane is divided into 9540 finite elements. The four node quadrilateral membrane element (shell63) with six degree of freedom in each node is used to realize the membrane. It is shown by Noga (Noga 2010) that satisfactory results are achieved by realizing the tensile forces as follows. On each node lying on the outer edge is imposed a concentrated tensile force $N_{0}$ in the radial direction. The proper value of the force is selected experimentally by numerical simulation. The boundary conditions are realized as follows. All nodes lying on the outer edge of the 
membrane are simply supported with a possibility to slide freely in the radial direction, and all nodes lying on the inner edge of the membrane are pinned.

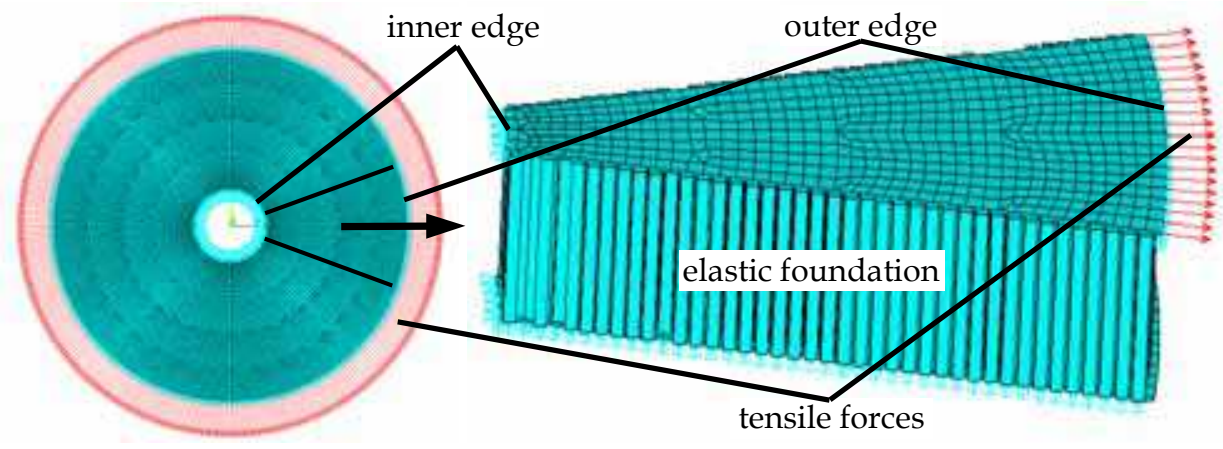

Fig. 28. Second finite element model of the system

The second FE model is the same as the first, but the execution of the Winkler foundation is different. Each massless spring is modeled by using a bar (link) element. The values of the dimension parameters of the bars are established a priori. The proper value of the Young's modulus $E_{f}$ of each bar is selected experimentally to minimize the frequency error (4).

\subsection{Numerical analysis}

Numerical solutions for free vibration analysis of the annular membrane attached to elastic foundation models suggested earlier are computed. For each approach, only the first ten natural frequencies and mode shapes are discussed. Table 8 presents the parameters characterizing the system under study.

\begin{tabular}{|c|c|c|c|c|c|c|}
\hline$a[\mathrm{~m}]$ & $b[\mathrm{~m}]$ & $h[\mathrm{~m}]$ & $\rho\left[\mathrm{kg} / \mathrm{m}^{3}\right]$ & $E[\mathrm{~Pa}]$ & $v$ & $\mathrm{~N}[\mathrm{~N} / \mathrm{m}]$ \\
\hline 0.5 & 0.1 & 0.002 & $2.7 \cdot 10^{3}$ & $7 \cdot 10^{10}$ & 0.32 & 500 \\
\hline
\end{tabular}

Table 8. Parameters characterizing the system under study

In the table, $E$ and $v$ are, the Young's modulus and Poisson ratio, respectively. For the continuous model the natural frequencies are determined from numerical solution of the equations (13) and (14). The results of the calculation are shown in Table 9.

\begin{tabular}{|c|c|c|c|c|c|c|c|}
\hline & \multicolumn{7}{|c|}{$n$} \\
\hline \multirow{3}{*}{$m$} & & 0 & 1 & 2 & 3 & 4 & 5 \\
\cline { 2 - 8 } & 1 & 12.0828 & 13.3304 & 16.2846 & 19.8242 & 23.4497 & 27.0413 \\
\cline { 2 - 8 } & 2 & 24.0425 & 24.8625 & 27.1393 & 30.3978 & & \\
\hline
\end{tabular}

Table 9. Natural frequencies of the system under study $\omega_{m n}^{e}[\mathrm{~Hz}]$ (exact model)

The natural frequencies and the frequency error presented in Tables $10-11$ are referred to the first FE model and are obtained for $N_{0}=4.8[N]$. 


\begin{tabular}{|c|c|c|c|c|c|c|c|}
\hline & \multicolumn{7}{|c|}{$n$} \\
\hline \multirow{3}{*}{$m$} & & 0 & 1 & 2 & 3 & 4 & 5 \\
\cline { 2 - 8 } & 1 & 12.486 & 13.516 & 16.094 & 19.377 & 22.861 & 26.359 \\
\cline { 2 - 8 } & 2 & 24.85 & 25.486 & 27.302 & 30.046 & & \\
\hline
\end{tabular}

Table 10. Natural frequencies of the system under study $\omega_{m n}^{f}[\mathrm{~Hz}]$

\begin{tabular}{|c|c|c|c|c|c|c|c|}
\hline & \multicolumn{7}{|c|}{$n$} \\
\hline \multirow{3}{*}{$m$} & & 0 & 1 & 2 & 3 & 4 & 5 \\
\cline { 2 - 8 } & 1 & 3.337 & 1.3923 & -1.1704 & -2.2558 & -2.5105 & -2.5232 \\
\cline { 2 - 8 } & 2 & 3.3586 & 2.5078 & 0.5995 & -1.1573 & & \\
\hline
\end{tabular}

Table 11. Frequency error $\varepsilon_{m n}[\%]$

Tables 12 - 13 show the results related to the second FE model of the system under study and are obtained for $N_{0}=4.8[\mathrm{~N}]$ and $E_{f}=265[\mathrm{~Pa}]$.

\begin{tabular}{|c|c|c|c|c|c|c|c|}
\hline & \multicolumn{7}{|c|}{$n$} \\
\hline \multirow{3}{*}{$m$} & & 0 & 1 & 2 & 3 & 4 & 5 \\
\cline { 2 - 8 } & 1 & 12.485 & 13.515 & 16.093 & 19.376 & 22.86 & 26.358 \\
\cline { 2 - 8 } & 2 & 24.849 & 25.485 & 27.301 & 30.045 & & \\
\hline
\end{tabular}

Table 12. Natural frequencies of the system under study $\omega_{m n}^{f}[\mathrm{~Hz}]$

\begin{tabular}{|c|c|c|c|c|c|c|c|}
\hline & \multicolumn{7}{|c|}{$n$} \\
\hline \multirow{3}{*}{$m$} & & 0 & 1 & 2 & 3 & 4 & 5 \\
\cline { 2 - 8 } & 1 & 3.3287 & 1.3848 & -1.1766 & -2.2609 & -2.5147 & -2.5269 \\
\cline { 2 - 8 } & 2 & 3.3545 & 2.5038 & 0.5958 & -1.1606 & & \\
\hline
\end{tabular}

Table 13. Frequency error $\varepsilon_{m n}[\%]$

For both FE model cases the biggest difference between the exact and the FE solutions may be visible for the frequencies $\omega_{10}$ and $\omega_{20}$, respectively. For all cases the sequence of appearance of the natural frequencies refered to the adequate modes shapes is the same. Some modes of vibration corresponding to the presented pairs of natural frequencies are presented in Fig. 29 and Fig. 30, respectively.
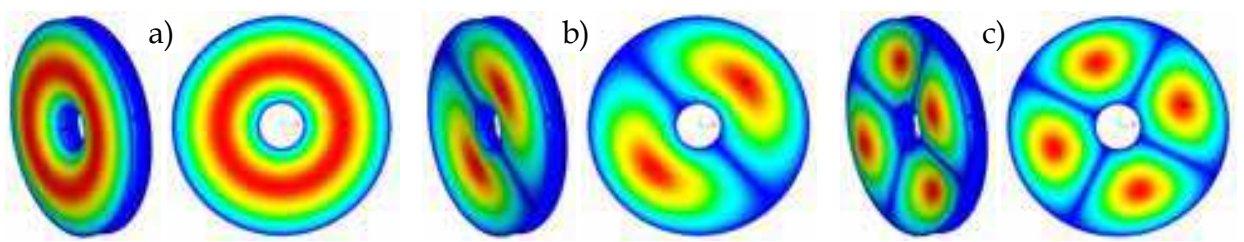

Fig. 29. Mode shapes corresponding to the frequencies: (a) $\omega_{10}$, (b) $\omega_{11}$, (c) $\omega_{12}$ 

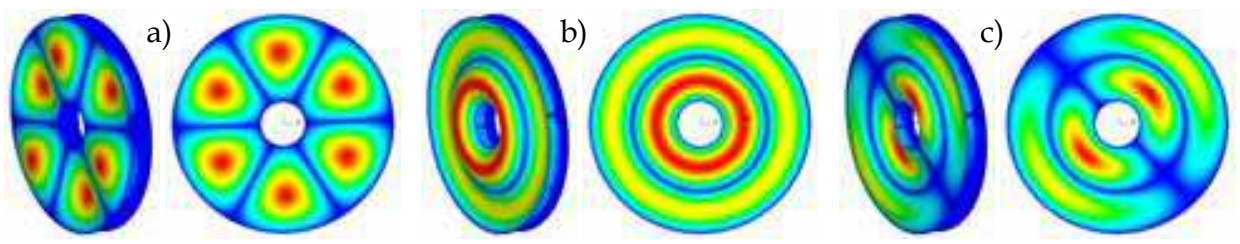

Fig. 30. Mode shapes corresponding to the frequencies: (a) $\omega_{13}$, (b) $\omega_{20}$, (c) $\omega_{21}$

\section{Conclusion}

This work deals with the analysis of the free vibration of selected mechanical systems with complex design and geometry. Three different types of mechanical systems are taken into consideration, i.e.: a fatigue test rig for aviation gear boxes, a gas turbine blade and an annular membrane attached to Winkler elastic foundation. Design and creation of modern devices require the use of advanced numerical software based on the finite element method. It is specially addressed to modern aviation test rigs and other aviation parts like turbine blades. This allows the specific design features and complex geometry of the rig and blade to be taken into consideration. Two FE models of the test rig are investigated. Some portion of the natural frequencies and mode shapes obtained from numerical calculations are verified with experimental investigations. Considering the obtained results, a small difference can be observed in both cases between the numerical and experimental results related to the natural frequencies connected with the vertical vibration forms of the rig. For both models, lower consistency appears for the natural frequencies connected to the concurrent vibration in the base frame plane of the rig. The second FE model of the rig gives satisfactory insight on the dynamic behaviour of the rig. Further investigation will be oriented towards developing a numerical model allowing better consistency between numerical and experimental results. The FE model of the analyzed blade is verified during an endurance test with accuracy to the first natural frequency. When analyzing the obtained results, it can be seen that performing the lobes on the blade and the disk sector has an influence on the value of blade natural frequencies. Based on the classical theory of membranes, a comprehensive vibration analysis of an annular membrane attached to elastic foundation of the Winkler type is investigated. The Bernoulli - Fourier method is applied to derive the eigenvalue problem. Two FE models of the system under investigation are prepared and discussed. The exact solution is used to verify the developed FE models. The numerical solution demonstrated that the second FE model would be better to simulate the free vibration of the membrane resting on the elastic foundation. Moreover, the second FE model can simulate the vibration of the system with a mass elastic layer. It is important to note that the data presented in this chapter have practical meaning for design engineers.

\section{Acknowledgment}

MSc Eng Mieczysław Kozłowski and MSc Eng Wojciech Obrocki - WSK PZL Rzeszów S.A. employees - took part in the experimental investigations. 


\section{References}

Allara, M. (2009). A Model for the Characterization of Friction Contacts in Turbine Blades. Journal of Sound and Vibration, Vol. 320, No. 3, pp. 527-544, ISSN 0022-460X

Ansell, A. (2005). The Dynamic Element Method for Analysis of Frame and Cable Type Structures. Engineering Structures, Vol. 27, No. 13, pp. 1906-1915, ISSN 0141-0296

Chung, W. \& Sotelino, E. (2006). Three Dimensional Finite Element Modelling of Composite Girder Bridges. Engineering Structures, Vol. 28, No. 1, pp. 63-71, ISSN 0141-0296

De Silva, C. (2005). Vibration and Shock Handbook, Taylor \& Francis, ISBN 978-0-8493-1580-0, Boca Raton, USA

Jaffrin, M. (2008). Dynamic Shear - Enhanced Membrane Filtration: a Review of Rotating Disks, Rotating Membranes and Vibrating Systems. Journal of Membrane Science, Vol. 324, No. 1, pp. 7-25, ISSN 0376-7388

Friswell, M. \& Mottershead, J. (1995). Finite Element Model Updating in Structural Dynamics, Kluwer Academic Publishers, ISBN 0-7923-3431-0, Dordrecht, Netherlands

Kaliski, S. (1966). Vibration and Waves in Solids, IPPT PAN, Warsaw, Poland (in Polish)

Łączkowski, R. (1974). Vibration of Thermic Turbine Elements, WNT, Warsaw, Poland (in Polish)

Markowski, T.; Noga, S. \& Rudy, S. (2010). Numerical Model of Aviation Gearbox Test Rig in a Closed Loop Configuration. Aviation, Vol. 14, No. 1, pp. 3-11, ISSN 1648-7788

Noga, S. (2008). Free Transverse Vibration analysis of an Annular Membrane. Vibrations in Physical Systems, Vol. XXIII, pp. 283-288, ISBN 978-83-89333-35-3

Noga, S. (2010). Free Transverse Vibration Analysis of an Elastically Connected Annular and Circular Double - Membrane Compound System. Journal of Sound and Vibration, Vol. 329, No. 9, pp. 1507-1522, ISSN 0022-460X (a)

Noga, S. (2010). Free Vibrations of an Annular Membrane Attached to Winkler Foundation. Vibrations in Physical Systems, Vol. XXIV, pp. 295-300, ISBN 978-83-89333-35-3 (b)

Rao, S. (2007). Vibration of Continuous Systems, Wiley, ISBN-13: 978-0471771715, Hoboken, USA

Rossit, C.; La Malfa, S. \& Laura, P. (1998). Antisymmetric Modes of Vibrations of Composite, Doubly - Connected Membranes. Journal of Sound and Vibration, Vol. 217, No. 1, pp. 191-195, ISSN 0022-460X

Rudy, S. \& Kowalski, T. (1998). Analysis of Contact Phenomenas and Free Vibration Forms of a Blade of Turbine Engine with a Use of FEM, Rotary Fluid - Flow Machines: proceedings conference, pp. 105-113, ISBN 83-7199-059-6, Rzeszów, Poland (in Polish)

Tack, J.; Verkerke, G.; van der Houwen, E.; Mahieu, H. \& Schutte, H. (2006). Development of a Double - Membrane Sound Generator for Application in a Voice - Producing Element for Laryngectomized Patients. Annals of Biomedical Engineering, Vol. 34, No. 12, pp. 1896-1907, ISSN 0090-6964

Toufine, A.; Barrau, J. \& Berthillier M. (1999). Dynamic Study of a Simplified Mechanical System with Presence of Dry Friction. Journal of Sound and Vibration, Vol. 225, No. 1, pp. 95-109, ISSN 0022-460X

Sinha, S.; Turner, K. (2011). Natural Frequencies of a Pre - twisted Blade in a Centrifugal Force Field. Journal of Sound and Vibration, Vol. 330, No. 11, pp. 2655-2681, ISSN 0022-460X 
Živanović, S.; Pavic, A. \& Reynolds, P. (2007). Finite Element Modelling and Updating of a Lively Footbridge: The Complete Process. Journal of Sound and Vibration, Vol. 301, No. 1-2, pp. 126-145, ISSN 0022-460X

Zembaty, Z.; Kowalski, M. \& Pospisil, S. (2006). Dynamic Identification of a Reinforced Concrete Frame in Progressive State of Damage. Engineering Structures, Vol. 28, No. 5, pp. 668-681, ISSN 0141-0296 


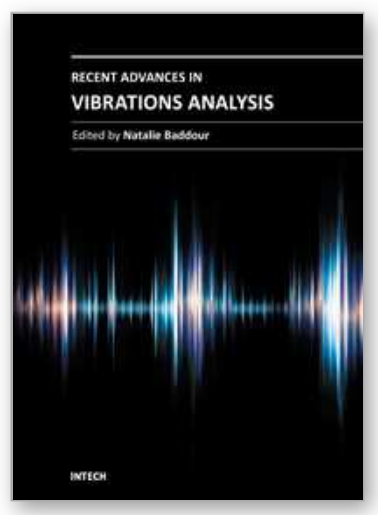

\author{
Recent Advances in Vibrations Analysis \\ Edited by Dr. Natalie Baddour
}

ISBN 978-953-307-696-6

Hard cover, 236 pages

Publisher InTech

Published online 09, September, 2011

Published in print edition September, 2011

This book covers recent advances in modern vibrations analysis, from analytical methods to applications of vibrations analysis to condition monitoring. Covered topics include stochastic finite element approaches, wave theories for distributed parameter systems, second other shear deformation theory and applications of phase space to the identifications of nonlinearities and transients. Chapters on novel condition monitoring approaches for reducers, transformers and low earth orbit satellites are included. Additionally, the book includes chapters on modelling and analysis of various complex mechanical systems such as eccentric building systems and the structural modelling of large container ships.

\title{
How to reference
}

In order to correctly reference this scholarly work, feel free to copy and paste the following:

Tadeusz Markowski, Stanisław Noga and Stanisław Rudy (2011). Modelling and Vibration Analysis of Some Complex Mechanical Systems, Recent Advances in Vibrations Analysis, Dr. Natalie Baddour (Ed.), ISBN: 978953-307-696-6, InTech, Available from: http://www.intechopen.com/books/recent-advances-in-vibrationsanalysis/modelling-and-vibration-analysis-of-some-complex-mechanical-systems

\section{INTECH}

open science | open minds

\section{InTech Europe}

University Campus STeP Ri

Slavka Krautzeka 83/A

51000 Rijeka, Croatia

Phone: +385 (51) 770447

Fax: +385 (51) 686166

www.intechopen.com

\section{InTech China}

Unit 405, Office Block, Hotel Equatorial Shanghai

No.65, Yan An Road (West), Shanghai, 200040, China

中国上海市延安西路65号上海国际贵都大饭店办公楼405单元

Phone: +86-21-62489820

Fax: +86-21-62489821 
(C) 2011 The Author(s). Licensee IntechOpen. This chapter is distributed under the terms of the Creative Commons Attribution-NonCommercialShareAlike-3.0 License, which permits use, distribution and reproduction for non-commercial purposes, provided the original is properly cited and derivative works building on this content are distributed under the same license. 